\title{
Constitutive activation of MAPK/ERK inhibits prostate cancer cell proliferation through upregulation of BRCA2
}

\author{
LOREDANA MORO $^{1}$, ARNALDO A. ARBINI $^{2}$, ERSILIA MARRA $^{1}$ and MARGHERITA GRECO ${ }^{1}$ \\ ${ }^{1}$ Institute of Biomembranes and Bioenergetics, National Research Council (C.N.R.), Bari 70126, Italy; \\ ${ }^{2}$ Department of Pathology and Laboratory Medicine, University of Rochester, \\ School of Medicine and Dentistry, Rochester, NY 14642, USA
}

Received August 7, 2006; Accepted September 28, 2006

\begin{abstract}
BRCA2 is central to an utterly diverse biological behavior elicited after integrin-mediated normal and prostate cancer cell adhesion to basement membrane (BM) and extracellular matrix (ECM) proteins. Unlike normal cells, adhesive stimuli in cancer cells activate PI 3-kinase/AKT signaling resulting in BRCA2 degradation and unchecked cancer cell proliferation and metastasis. However, the precise mechanisms involved in normal BRCA2 homeostasis are unknown. We investigated ERK and AKT phosphorylation in normal (PNT1A) and cancer (PC-3) prostate cells after adhesion to ECM and the effects upon BRCA2 and cell proliferation. PNT1A cell adhesion to ECM triggered MAPK/ERK signaling resulting in upregulation of BRCA2 mRNA and protein, with negligible effects upon cell proliferation. Disruption of MAPK/ERK with PD98059 prevented any BRCA2 upregulation inhibiting DNA synthesis below basal levels. PC-3 cells exhibited a defective MAPK/ERK pathway that was unresponsive to adhesion to the ECM, which instead triggered PI 3-kinase/AKT signaling leading to BRCA2 protein depletion and cell proliferation. Reconstitution of MAPK/ERK by recombinant expression of a constitutively active form of MAPK kinase 1 (MEK1) effectively reversed the neoplastic phenotype by increasing BRCA2 expression and preventing any aberrant cell proliferation at rest and upon interaction with ECM proteins. Our results suggest that aberrant loss of MAPK/ERK activity in prostate cancer may play a pivotal role in the malignant phenotype, and provide evidence that interventions aimed at bypassing the signaling block are able to effectively reverse neoplastic unchecked cell proliferation.
\end{abstract}

Introduction

Correspondence to: Dr Loredana Moro, Institute of Biomembranes and Bioenergetics, National Research Council (C.N.R.), Via Amendola 165/A, 70126 Bari, Italy

E-mail: 1.moro@ibbe.cnr.it

Key words: MAPK/ERK, BRCA2, cell proliferation, extracellular matrix, cancer
In adult human prostate, the relationship between cell proliferation and cell death is a precise balancing act that prevents organ involution or overgrowth. Upon neoplastic transformation this equilibrium is ultimately deranged leading to abnormal organ growth and tumor formation (1). Both processes are exquisitely regulated by a continuous cross-talk between cells and the surrounding microenvironment. Chemical stimuli such as growth factors or physical interaction with BM or ECM proteins activate diverse cell signaling pathways that exert control over cell proliferation and survival (2-5). The MAPK/ERK (mitogen-activated protein kinase/ extracellularregulated kinase) and PI 3-kinase (phosphatidyl inositol 3kinase)/AKT signaling pathways are two major transducers of extracellular stimuli through modulation of the expression of genes exerting stringent control upon cell survival, motility, and cell proliferation $(6,7)$. ERK accumulation in the nucleus regulates transcription factors involved in DNA synthesis (8), cell differentiation $(9,10)$, and promotion of acinar formation in the normal prostate (11). Similarly, the PI 3-kinase/AKT signaling pathway regulates many cellular processes that are critically involved in cell proliferation and survival (12). The role of these pathways in oncogenesis has been extensively investigated and altered expression/activity of many of their components has been implicated in human cancer (13).

$B R C A 2$ is a tumour suppressor gene whose inactivation accounts for an increased risk of developing breast and ovarian cancer in women and prostate cancer in men (14-16). In addition to its well known role in orchestrating DNA repair, there is preliminary evidence suggesting that BRCA2 may also suppress tumour development by inhibiting cancer cell growth (17). Previously, we described a novel pathological mechanism whereby prostate carcinoma cell interaction with $\mathrm{BM}$ proteins or to the osseous ECM protein collagen type I (COL1) would promote cancer cell proliferation through depletion of BRCA2 protein. The downregulatory effect upon BRCA2 results from activation of the PI 3-kinase pathway, which promotes Skp2-mediated BRCA2 ubiquitination and degradation in the proteasome, and could be prevented by intervening to disrupt this pathway $(3,5)$. This aberrant behavior is exclusive to cancer cells since normal prostate cell adhesion to ECM proteins does not cause depletion of BRCA2 protein or increase in cell proliferation $(3,5)$. 
In this study, we concentrated our effort to understand the biological mechanisms that may affect BRCA2 homeostasis in normal cells, and its relationship with cell proliferation. We demonstrate that unlike cancer cells, normal prostate cell adhesion to ECM induces activation of the MAPK/ERK pathway, which results in BRCA2 transcriptional upregulation and controlled cell growth. Furthermore, cancer cell transfection with a constitutively active MAPK/ERK is sufficient to reverse the neoplastic phenotype by upregulating BRCA2 and blocking any abnormal cell proliferation upon adhesion to ECM proteins.

\section{Materials and methods}

Cell culture. PNT1A cells (a human prostate normal cell line established by immortalization of normal adult prostate epithelial cells) and PC-3 cells (a human prostate carcinoma cell line derived from a bone metastasis) were kept in culture as described previously $(3,18)$.

Immunoblot analysis. PNT1A and PC-3 cells were grown onto laminin-1 (LN-1, $10 \mu \mathrm{g} / \mathrm{ml})$, COL1 $(10 \mu \mathrm{g} / \mathrm{ml})$ or collagen type $4(\mathrm{COL} 4 ; 10 \mu \mathrm{g} / \mathrm{ml})$ and then lysed in phosphatebuffered saline (PBS, pH 7.4) containing 1\% Nonidet P40, $2 \mathrm{mM}$ phenylmethylsulfonyl fluoride, $10 \mu \mathrm{g} / \mathrm{ml}$ aprotinin, $10 \mu \mathrm{g} / \mathrm{ml}$ leupeptin, $10 \mathrm{mM}$ sodium fluoride, $1 \mathrm{mM}$ sodium orthovanadate, and $5 \mathrm{mM}$ sodium pyrophosphate. Where indicated, cells were pre-treated at $37^{\circ} \mathrm{C}$ with the MAPK/ERK kinase 1 (MEK1) inhibitor PD98059 (50 $\mu \mathrm{M}$; Calbiochem, Darmstadt, Germany), or the PI 3-kinase inhibitors wortmannin (0.1 $\mu \mathrm{M}$; Sigma), LY294002 (10 $\mu \mathrm{M}$; Calbiochem), or solvent alone (dimethyl sulfoxide, DMSO). The protein content of each lysate was quantified using the Bio-Rad Dc protein assay reagent (Bio-Rad, Richmond, CA) according to the manufacturer's protocol. Protein extracts $(100 \mu \mathrm{g})$ were electrophoresed through 6 or $10 \%$ SDS-polyacrylamide gel under reducing conditions according to Laemmli (19) and transferred to polyvinylene difluoride membranes (Millipore, Bedford, MA) in $25 \mathrm{mM}$ Tris and $192 \mathrm{mM}$ glycine ( $\mathrm{pH}$ 8.3) containing 20\% methanol. Membranes were blotted with either $1 \mu \mathrm{g} / \mathrm{ml}$ polyclonal rabbit anti-BRCA2 antibody (H-300; Santa Cruz Biotechnology, Santa Cruz, CA), $10 \mu \mathrm{g} / \mathrm{ml}$ monoclonal antibody to $\beta$-tubulin (Sigma), $1 \mu \mathrm{g} / \mathrm{ml}$ polyclonal rabbit anti-phospho-AKT-Ser 473 antibody (Santa Cruz Biotechnology), $1 \mu \mathrm{g} / \mathrm{ml}$ polyclonal rabbit anti-AKT $1 / 2$ antibody (H-136; Santa Cruz Biotechnology), $0.2 \mu \mathrm{g} / \mathrm{ml}$ antiphospho-ERK monoclonal antibody (E-4; Santa Cruz Biotechnology), $0.2 \mu \mathrm{g} / \mathrm{ml}$ polyclonal rabbit anti-ERK2 antibody (C-14; Santa Cruz Biotechnology) for $16 \mathrm{~h}$ at $4^{\circ} \mathrm{C}$ in Trisbuffered saline/Tween-20 (TBS-T) (20 mM Tris, $\mathrm{pH} 7.5$, $150 \mathrm{mM} \mathrm{NaCl}, 0.1 \%$ Tween-20). Membranes were washed thrice in TBS-T and incubated with a 1:2500 dilution of horseradish-peroxidase-conjugated goat affinity-purified antibody to either rabbit or mouse IgG (Amersham Biosciences, Milan, Italy) for $1 \mathrm{~h}$ at room temperature. Afterwards, proteins were visualized using the enhanced chemiluminescent system (ECL, Amersham Biosciences) according to the manufacturer's instructions. Densitometric values from immunoreactive bands were obtained using a GS-700 imaging densitometer (Bio-Rad).
RNA extraction and RT-PCR. Cells were plated onto LN-1, COL1 or COL4, washed twice with cold PBS and total cellular RNA was isolated using the TRIzol reagent (Invitrogen Life Technologies) following the manufacturer's instructions. The amount of BRCA2 mRNA was measured by semi-quantitative reverse transcription as described (3). Glyceraldehyde 3-phosphate dehydrogenase (GAPDH) RT-PCR was performed as control (3).

$\left[{ }^{3} H\right]$ Thymidine incorporation. Thymidine incorporation assays were utilized to assess cell proliferative index. Briefly, after 24-h starvation, cells were plated in 96-well plates (10,000 cells/well) and grown for $15 \mathrm{~h}$ either on plastic (PL), LN-1, COL1 or COL4-coated wells. Where indicated, cells were preincubated for $1 \mathrm{~h}$ at $37^{\circ} \mathrm{C}$ with wortmannin, PD98059 or solvent alone (DMSO), before plating. During the last $3 \mathrm{~h}$ of the $15-\mathrm{h}$ culture, cells were pulsed with $1 \mu \mathrm{Ci} / \mathrm{ml}$ methyl$\left[{ }^{3} \mathrm{H}\right]$ thymidine (Amersham Biosciences), washed thrice with PBS at $0^{\circ} \mathrm{C}$, and dissolved in $10 \%$ SDS. Radioactivity was measured in a scintillation counter (Beckman Instruments).

Transient transfection. Cells were seeded into 6-well dishes at $4-5 \times 10^{5}$ cells/well. After $24 \mathrm{~h}$, transient transfections were performed using Lipofectamine 2000 (Invitrogen) according to the manufacturer's instructions. The DNA sequence against which small interfering RNA (siRNA) for BRCA2 was created is AACAACAAUUACGAACCAAACUU (3). Doublestranded RNA was transfected into the cells as $0.3 \mu \mathrm{g}$ of siRNA/well. Transient transfections with wild-type BRCA2 cDNA (a kind gift of Dr M.C. Hung, University of Texas M.D. Anderson Cancer Center, Houston), constitutively active MEK1 cDNA (a generous gift of Dr M. Cobb, University of Texas, Southwestern Medical Center, Dallas), or empty vector (pcDNA3, Invitrogen) were performed as described previously (3). Cells were harvested 36-96 h after transfection and used in immunoblotting, RT-PCR and $\left[{ }^{3} \mathrm{H}\right]$ thymidine incorporation assays.

Statistical analysis. Data are reported as the mean \pm SE. Statistical analysis was performed by the Student's t-test. All experiments were repeated at least twice.

\section{Results}

PNT1A cell adhesion to ECM triggers ERK phosphorylation. Epithelial cell interaction with adhesive substrates has been shown to activate the MAPK/ERK $(20,21)$ and PI 3 kinase/AKT signaling pathways $(22,23)$. Prostate cells are no exception and normal PNT1A cells exhibit detectable levels of ERK phosphorylation at rest by Western blot analysis with anti-phospho-ERK. After adhesion to the BM protein $\mathrm{LN}-1$, these levels increased by 2.2 -fold after $2.5 \mathrm{~h}$ and remained elevated for up to $6 \mathrm{~h}$ (Fig. 1). Basal PI 3kinase phosphorylation levels were also detectable at rest as measured by Western blotting with anti-phospho-Ser 473 AKT. However, they did not show any variations after cell adhesion to LN-1 (Fig. 1). On the other hand, PC-3 cells were characterized by complete absence of MAPK/ERK activity at rest, and no changes ensued after cell adhesion to LN-1 (Fig. 1). Instead, they showed 2-fold higher basal 

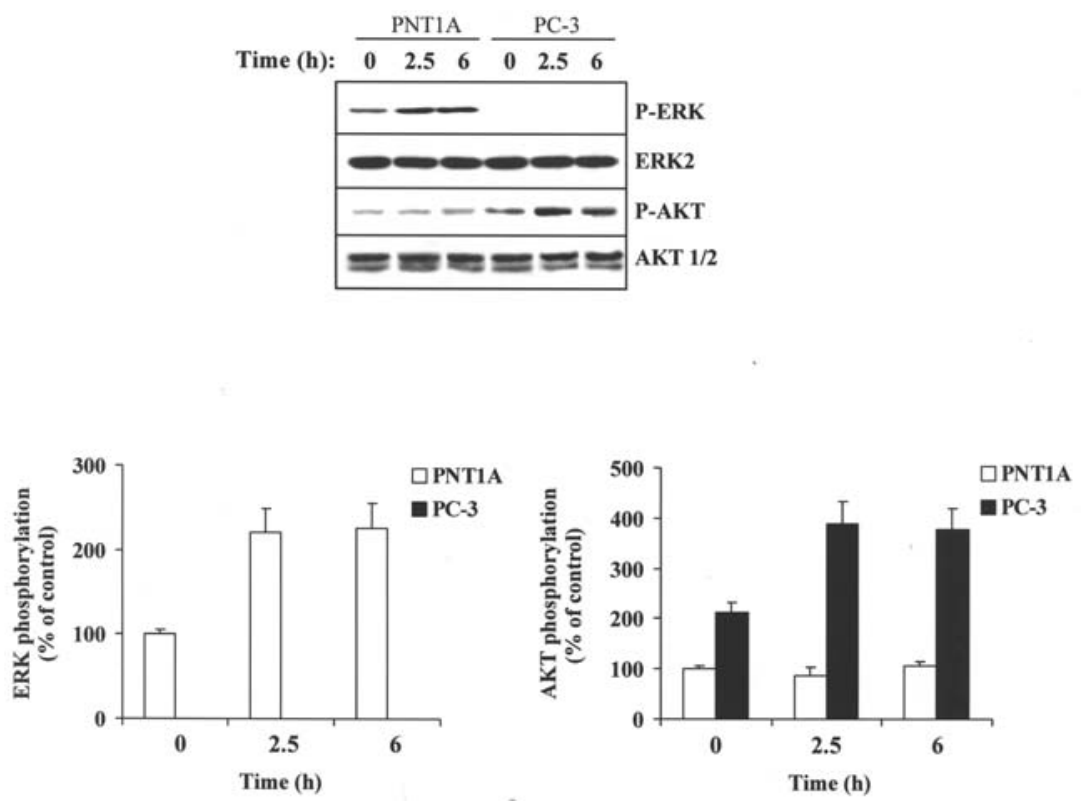

Figure 1. PNT1A cell adhesion to extracellular matrix proteins triggers ERK phosphorylation. PNT1A and PC-3 cells were allowed to adhere to laminin-1 (LN-1) at $37^{\circ} \mathrm{C}$ for 0 to $6 \mathrm{~h}$, washed, and lysed. After $10 \%$ SDS-PAGE proteins were transferred onto membranes and probed with anti-phospho-ERK (P-ERK) or antiphospho-Ser 473 AKT (P-AKT). Subsequently, membranes were stripped and blotted with anti-ERK2 (ERK2) or anti-AKT 1/2 (AKT 1/2) as control. The blots are representative of three independent experiments. To construct the lower graphic representation, phosphorylation levels were quantitated and reported as percentage of phosphorylated protein at $0 \mathrm{~h}$ in PNT1A cells, set to represent $100 \%$. Data are expressed as mean \pm SE of three independent experiments.

A
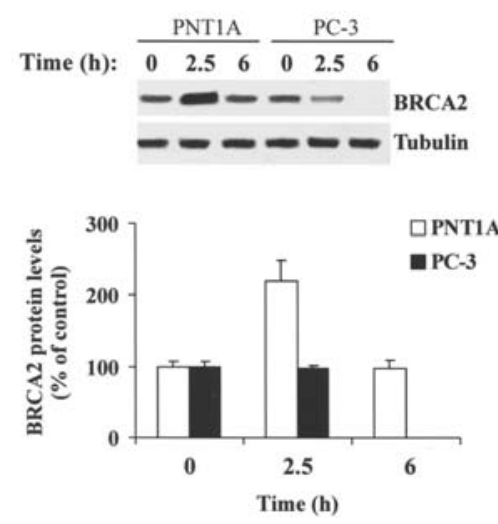

B
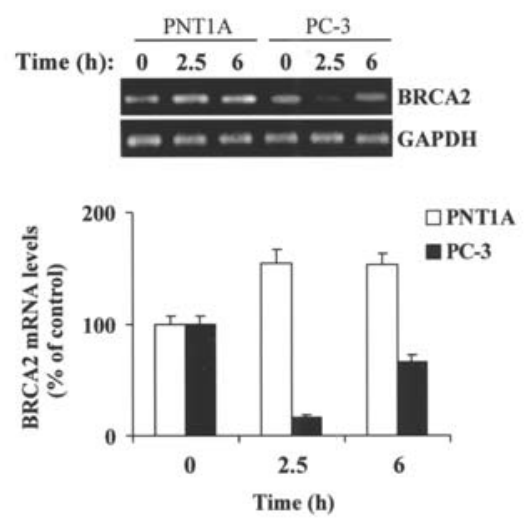

Figure 2. PNT1A cell adhesion onto extracellular matrix proteins increases BRCA2 mRNA and protein levels. (A) PNT1A and PC-3 cells were allowed to adhere to laminin-1 (LN-1) for the indicated time, washed, and processed for immunoblotting. Membranes were probed with anti-BRCA2 antibody using B-tubulin as loading control. The blots are representative of three independent experiments. At the bottom, BRCA2 protein levels were quantitated and reported as percentage of the amount of protein at $0 \mathrm{~h}$, set to represent $100 \%$. Data are expressed as mean \pm SE of three independent experiments. (B) PNT1A and PC-3 cells were allowed to adhere to LN-1 for the indicated time, washed, and processed for BRCA2 mRNA semi-quantitative RT-PCR. Glyceraldehyde 3-phosphate dehydrogenase (GAPDH) mRNA RT-PCR was used as internal control. At the bottom, BRCA2 mRNA levels were reported as percentage of transcript at $0 \mathrm{~h}$, set to represent $100 \%$. Data are expressed as mean $\pm \mathrm{SE}$ of three independent experiments.

AKT phosphorylation levels when compared to PNT1A, and these levels doubled after $2.5 \mathrm{~h}$ of substrate adhesion remaining highly phosphorylated for as long as $6 \mathrm{~h}$. Similar behavior was noted onto COL1 (data not shown).

PNT1A cell adhesion to ECM increases BRCA2 $m R N A$ and protein levels. To investigate whether cell interaction with ECM proteins has an effect upon BRCA2 expression, PNT1A and $\mathrm{PC}-3$ cells were grown onto plates coated with $\mathrm{LN}-1$. In normal PNT1A cells, BRCA2 levels doubled after $2.5 \mathrm{~h}$ but by $6 \mathrm{~h}$ they had returned to basal levels (Fig. 2A). This effect was likely related to transcriptional activation since BRCA2 mRNA increased by $\sim 55 \%$ at $2.5 \mathrm{~h}$ and remained elevated throughout the experiment (Fig. 2B). On the contrary, PC-3 cells responded to the adhesive substrate by swiftly removing any BRCA2 protein to undetectable amounts after $6 \mathrm{~h}$. This resulted largely from a mechanism acting at the posttranscriptional level as BRCA2 mRNA levels after $6 \mathrm{~h}$ of adhesion in concomitant absence of BRCA2 protein were $\sim 65 \%$ of basal levels (Fig. 2B). However, a transcriptional 
A

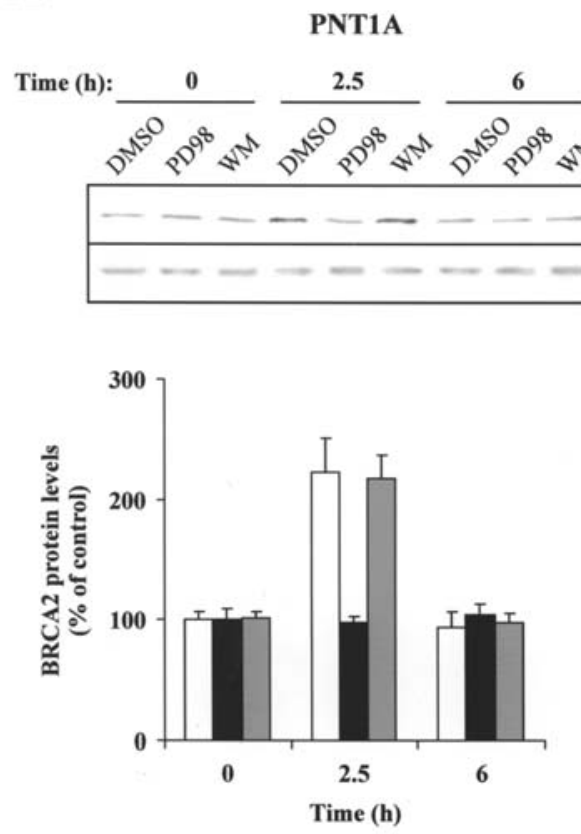

B

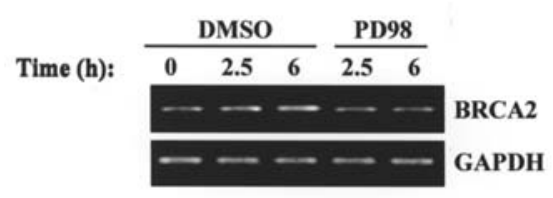

Figure 3. MAPK/ERK modulates BRCA2 expression in PNT1A cells. (A) PNT1A and PC-3 cells were pre-treated with $50 \mu \mathrm{M}$ PD98059 (PD98), a MEK1 inhibitor, or $0.1 \mu \mathrm{M}$ wortmannin (WM), a PI 3-kinase inhibitor, or the solvent alone (DMSO), then allowed to adhere to laminin-1 (LN-1) for the indicated times, washed, lysed and processed for immunoblotting. Membranes were probed with anti-BRCA2 antibody using B-tubulin as loading control. At the bottom, BRCA2 protein levels were reported as percentage protein at $0 \mathrm{~h}$, set to represent $100 \%$. Data are expressed as mean $\pm \mathrm{SE}$ of three independent experiments. (B) PNT1A cells were pre-treated for $1 \mathrm{~h}$ at $37^{\circ} \mathrm{C}$ with $50 \mu \mathrm{M}$ PD98059 (PD98) or the solvent alone (DMSO), then allowed to adhere to $\mathrm{LN}-1$ for the indicated times, washed and processed for BRCA2 mRNA semi-quantitative RT-PCR. Glyceraldehyde 3-phosphate dehydrogenase (GAPDH) mRNA RT-PCR was used as internal control. At the bottom, BRCA2 mRNA levels were reported as percentage of the amount of transcript at $0 \mathrm{~h}$ in DMSO-treated cells, set to represent $100 \%$. Data are expressed as mean $\pm \mathrm{SE}$ of three independent experiments.

downregulation contributes to this effect within the first $2.5 \mathrm{~h}$ as measurable mRNA rapidly decreased by $\sim 84 \%$ after $2.5 \mathrm{~h}$, to subsequently recover to basal levels. Similar behaviour was noted onto COL1 (3).

MAPK/ERK modulates BRCA2 expression in PNT1A cells. To investigate whether BRCA2 upregulation in PNT1A cells is linked to the observed increase in ERK activity, we determined the effects of the ERK1/2 upstream inhibitor PD98059 on BRCA2 protein levels (Fig. 3). Pre-incubation of PNT1A cells with PD98059 for $1 \mathrm{~h}$ completely inhibited ERK phosphorylation at rest (data not shown) and prevented any increase in BRCA2 protein after $2.5 \mathrm{~h}$ adhesion to LN-1 (98\% $\pm 5 \%$ of basal levels; Fig. 3A) or to COL1 (data not shown). Furthermore, PD98059 prevented any increase in BRCA2 mRNA after adhesion to LN-1 (93\% and $97 \%$ of basal levels at 2.5 and $6 \mathrm{~h}$, respectively, Fig. 3B). PD98059 had no discernible effect upon PC-3 cells. Pharmacological inhibition of AKT phosphorylation in PC-3 cells with wortmannin or LY294002 (data not shown) had a positive effect upon BRCA2 protein, which increased by

4.3-fold after $2.5 \mathrm{~h}$ of adhesion to LN-1 (Fig. 3A). Inhibition of the PI 3-kinase did not affect BRCA2 protein levels in PNT1A cells.

Activation of MAPK/ERK sustains normal prostate cell proliferation after interaction with ECM. To investigate whether MAPK/ERK signaling has any effect upon normal PNT1A cell proliferation after interaction with $\mathrm{LN}-1$, we measured DNA incorporation of $\left[{ }^{3} \mathrm{H}\right]$ thymidine in presence or absence of PD98059. DNA synthesis in PNT1A cells onto LN-1 was indistinguishable from cells grown onto plastic (Fig. 4A). Nevertheless, this 'basal' level of $\left[{ }^{3} \mathrm{H}\right]$ thymidine incorporation was inhibited by $>90 \%(\mathrm{p}<0.0001)$ after MAPK/ERK inhibition with PD98059 (Fig. 4B). Furthermore, siRNA assays suggested that the cell growth inhibitory effect was mediated by the decrease in BRCA2. Since BRCA2 levels were completely knocked down four days after transfection with BRCA2 double-stranded RNA, we tested cell proliferation upon adhesive substrates at $48 \mathrm{~h}$, when BRCA2 levels were $\sim 60 \%$ of starting amounts (data not shown). As shown in Fig. 4C, new DNA synthesis decreased by $47 \%(\mathrm{p}<0.02)$. 
A

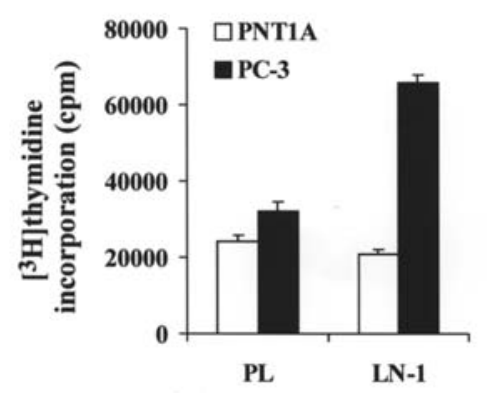

C

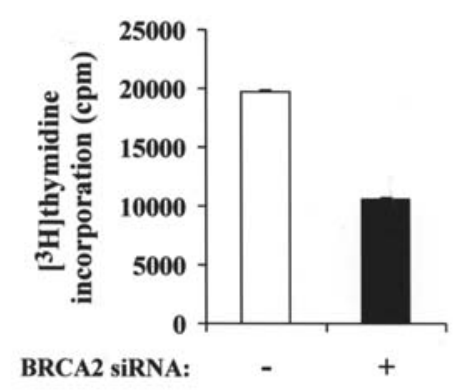

B

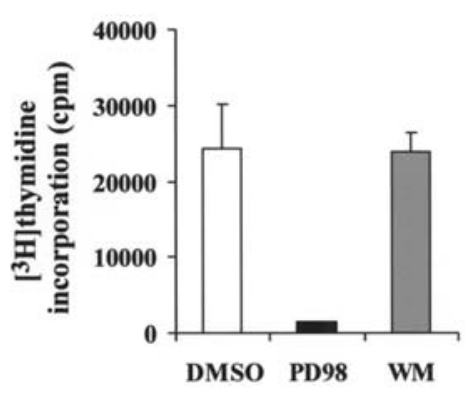

Figure 4. Activation of MAPK/ERK sustains normal prostate cell proliferation after interaction with extracellular matrix proteins. (A) PNT1A and PC-3 cells were allowed to adhere to either plastic (PL) or laminin-1 (LN-1) for $15 \mathrm{~h}$ and pulsed with $1 \mu \mathrm{Ci} /$ well methyl- $\left[{ }^{3} \mathrm{H}\right]$ thymidine during the last $3 \mathrm{~h}$. Cells were washed with cold medium, lysed, and cell remnants collected in scintillation vials for incorporated radioactivity measurement. (B) PNT1A cells preincubated with PD98059 (PD98), wortmannin (WM), or solvent alone (DMSO) were allowed to adhere to LN-1 for $15 \mathrm{~h}$ and pulsed as described above. Results are mean $\pm \mathrm{SE}$ of triplicate determinations. A representative experiment of three is shown. (C) PNT1A cells transfected to express an interfering RNA for BRCA2 or treated with the transfection reagent alone were allowed to adhere to $\mathrm{LN}-1$ for $15 \mathrm{~h}$ and pulsed as described above. Data are expressed as mean \pm SE of triplicate wells. A representative experiment of three is shown.
Inhibition of the PI 3-kinase pathway with wortmannin did not affect PNT1A cell proliferation (Fig. 4B). Comparable results were obtained onto COL1 (data not shown).

Constitutive activation of MAPK/ERK increases BRCA2 expression and inhibits DNA synthesis in prostate cancer cells. Since MAPK/ERK signaling seems to be crucial in BRCA2 homeostasis and controlled cell proliferative response upon normal cell interaction with ECM proteins, we hypothesized that ERK reconstitution into PC-3 cells may have an effect upon the neoplastic phenotype. To test this hypothesis, we transfected PC-3 cells with a constitutively active form of MAPK/ERK kinase 1 (MEK1) and measured $\left[{ }^{3} \mathrm{H}\right]$ thymidine incorporation onto PL, LN-1, COL4 and COL1. As shown in Fig. 5A, activation of the MAPK/ERK pathway resulted in a dramatic inhibition of cancer cell proliferation onto PL (81\% decrease, $\mathrm{p}<0.001)$ and prevented any proliferative response triggered by ECM proteins $(\mathrm{p}<0.001)$. MAPK/ERK-dependent inhibition of PC-3 cell proliferation was accompanied by a sustained increase in BRCA2 mRNA and protein levels at rest $(2.1$ - and 2 -fold increases, respectively; $\mathrm{p}<0.01)$ that persisted after $6 \mathrm{~h}$ onto adhesive proteins (Fig. 5B-C).

\section{Discussion}

Aberrant cancer cell interactions with BM and ECM proteins play a crucial role in the biology of metastasis (24). Reduced cell-cell interactions and increased cell adhesion to an adjacent BM confers motility, which along with the capacity of degrading/remodeling a BM directly relates to their metastatic potential (25). This cell behavior partly results from changes in the expression and/or usage of various adhesion receptors, including integrins (26). Integrins are transmembrane adhesion receptors for ECM proteins that not only provide physical anchoring cell support but play a pivotal role in triggering intracellular signaling in response to environmental changes through interactions with molecules such as GTPases, growth factor receptor tyrosine kinases $(2,4)$, MAPK/ERK 1/2 $(20,21)$, and PI 3-kinase/AKT $(22,23)$. Ras/Raf/MEK/ERK and PI 3-kinase/PTEN/AKT play critical roles in signal transduction that exert control upon cell differentiation, cell-cycle progression, and survival $(12,27)$. Mutations or constitutional activation of these pathways may lead to deregulated cell growth and cancer (28). Furthermore, these pathways may interact with each other to regulate growth, and in some cases tumorigenesis (29).

Normal prostate cells exhibit detectable levels of phosphorylated ERK and AKT at rest. Upon cell interaction with ECM proteins, signal transduction likely originating at integrin receptors results in 2.2-fold increase in MAPK/ERK phosphorylation with no detectable changes in AKT phosphorylation. The increase in ERK phosphorylation results in transient upregulation of BRCA2 protein expression. This is partly controlled at the transcriptional level as demonstrated by a concomitant increase in BRCA2 mRNA that is ablated after treatment with the MEK1 inhibitor PD98059. These data are in agreement with a recent report showing an increase in BRCA2 mRNA in response to ERK activation in normal mammary epithelial cells by analysis of the ERK1,2 transcriptome (30). Upregulation of BRCA2 mRNA levels has also been described in fibronectin-adherent immortalized murine embryonic stem cells in response to expression of $B 1 \mathrm{~A}$ integrin (31), the predominantly expressed $B 1$ integrin variant in normal prostate cells (18) and major cellular receptor for $\mathrm{LN}, \mathrm{COL}$ and fibronectin $(32,33)$. Whether expression of this integrin in absence of a ligand is sufficient to affect BRCA2 mRNA levels in normal prostate cells remains to be proven. However, preliminary evidence 
A

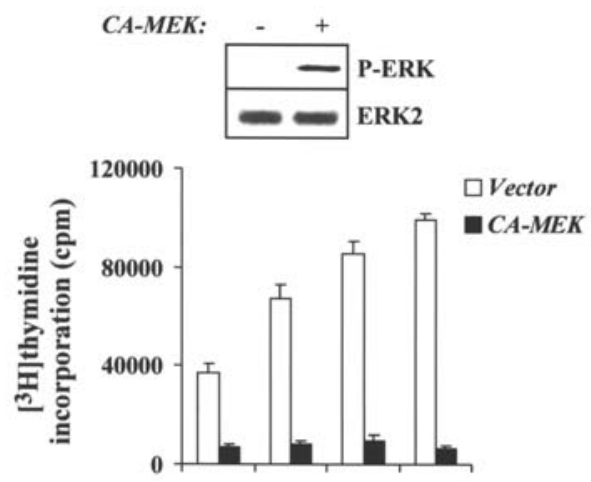

PL LN-1 COLA COL1

C
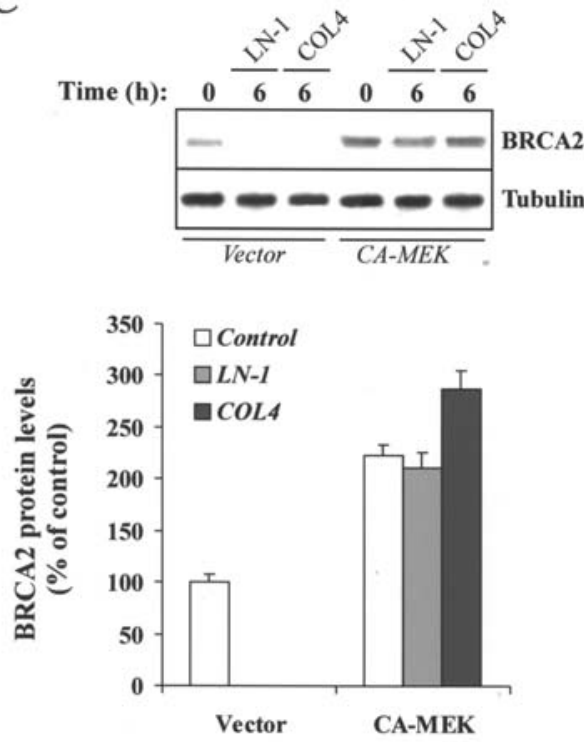

supporting this contention comes from experiments demonstrating upregulation of BRCA2 expression onto integrin-independent adhesive substrates (3). The biological processes sustained by basal ERK-mediated BRCA2 upregulation in normal prostate cells do not result in measurable cell proliferation by $\left[{ }^{3} \mathrm{H}\right]$ thymidine DNA incorporation assays. However, disruption of this axis with PD98059 is sufficient to halt any basal $\left[{ }^{3} \mathrm{H}\right]$ thymidine DNA incorporation, likely through interference with cell cycle progression. Available evidence suggests that BRCA2 mediates G2/M-phase control of the cell cycle by interacting with a novel protein, BRCA2-associated factor 35 (BRAF35), which is able to bind to branched DNA structures (34). The expression of BRAF25, a BRAF35 alternative spliced variant present in the normal prostate, is dramatically reduced in low-grade prostate cancer and completely absent in advanced prostate cancer $(35,36)$, suggesting that BRCA2/BRAF mediated regulation of cell cycle progression may be impaired after neoplastic transformation.

The homeostasis between BRCA2 expression, ERK and AKT signaling, and cell proliferation is derailed in prostate carcinoma. Our experiments demonstrate that PC-3 cells exhibit negligible levels of phosphorylated ERK that are
B

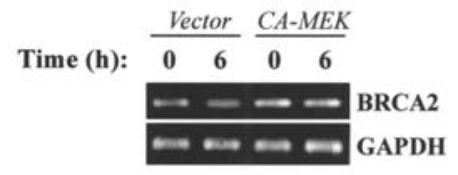

Figure 5. Constitutive activation of MAPK/ERK increases BRCA2 expression and inhibits DNA synthesis in prostate cancer cells. (A) PC-3 cells transfected with constitutively active form of MEK1 (CA-MEK) or empty vector were allowed to adhere to plastic (PL), laminin-1 (LN-1), collagen type IV (COL4) or collagen type I (COL1) for $15 \mathrm{~h}$, and pulsed with $1 \mu \mathrm{Ci} /$ well methyl- $\left[{ }^{3} \mathrm{H}\right]$ thymidine during the last $3 \mathrm{~h}$. Cells were washed with cold medium, lysed, and cell remnants collected in scintillation vials for incorporated radioactivity measurement. Data are expressed as mean $\pm \mathrm{SE}$ of triplicate wells. At the top, ERK phosphorylation was measured in PC-3 cells $24 \mathrm{~h}$ after transfection with CA-MEK by immunoblotting with a-phospho-ERK (P-ERK) antibody. Anti-ERK2 (ERK2) immunoblotting served as control. A representative experiment of three is shown. (B and C) PC-3 cells were transiently transfected with CA-MEK cDNA or empty vector (pcDNA3) for $24 \mathrm{~h}$, after which BRCA2 mRNA (B) and protein (C) expression were determined by RT-PCR and immunoblotting, respectively, before (Control) and after $6 \mathrm{~h}$ of adhesion to LN-1 (B and C) or COL4 (C). A representative experiment of three is shown. At the bottom of panel C, BRCA2 protein levels were quantitated and reported as percentage of protein at $0 \mathrm{~h}(\mathrm{Control})$, set to represent $100 \%$. Data are expressed as mean \pm SE of three independent experiments.

unresponsive to agonists such as cell adhesion onto ECM proteins. The new equilibrium in neoplastic cells seems to be one where integrin initiated signaling is transduced through PI 3-kinase/AKT pathway as demonstrated by high levels of phosphorylated AKT at basal state and after cell adhesion onto BM components LN-1, COL4 (5), and osseous COL1 (3). These results are also in agreement with previous studies reporting high levels of AKT phosphorylation and decreased ERK phosphorylation in vivo in samples from high-Gleason grade prostate cancer (37-39). A plausible explanation would relate to loss of PTEN (phosphatase and tensin homologue deleted from chromosome 10) (40) activity in PC-3 cells (41). PTEN is a lipid phosphatase that cleaves a D3 phosphate of PIP3, an important activator of AKT that when left unchecked engenders a constitutively active PI 3-kinase/AKT pathway (42). High levels of phosphorylated AKT would directly suppress Raf/MEK/ERK by phosphorylating and inactivating Raf-1, an upstream regulator of the MAPK/ERK pathway (29). Furthermore, we demonstrate herewith for the first time that the transfection of a constitutive active form of MAPK/ERK kinase 1 is sufficient to reverse the neoplastic PC-3 cell phenotype by inhibiting cancer cell proliferation at rest and preventing any inducible cell proliferation upon adhesion to ECM proteins. The restored homeostasis is likely related to newly found intracellular BRCA2 mRNA and protein replenishment, as suggested by our previous studies $(3,5)$. In this paradigm, BRCA2 seems to function by exercising a stringent control upon cell proliferation capable of positive and negative feedback in the normal cellular environment, and its absence due to neoplastic cell transformation results in unchecked cell proliferation that is triggered by PI 3-kinase/ AKT signaling after cell interaction with the ECM. These 
results would support recent reports suggesting a role for activated ERK in mediating drug-induced apoptosis or inhibition of cell proliferation in PC-3, as well as ovarian and breast cancer cells (43-47).

Our results suggest that loss of MAPK/ERK activity in prostate cancer plays a major role in the malignant phenotype, due in part to the ensuing loss of BRCA2 protein that leads to unchecked cancer cell proliferation upon cell interaction with $\mathrm{BM}$ and ECM proteins. Further studies aimed at elucidating the precise molecular mechanisms through which BRCA2 is able to function as a cellular check-point in normal and cancer cells may potentially uncover new molecular targets susceptible of modifying the natural history of prostate carcinoma.

\section{Acknowledgments}

We are grateful to Dr M.C. Hung for the BRCA2 cDNA construct and to Dr M. Cobb for the MEK construct. This work was supported by the MIUR-Contributi Straordinari di ricerca/aree obiettivo 1 grant (to E.M.).

\section{References}

1. Denmeade SR, Lin XS and Isaacs JT: Role of programmed (apoptotic) cell death during the progression and therapy for prostate cancer. Prostate 28: 251-265, 1996.

2. Goel HL, Fornaro M, Moro L, Teider N, Rhim JS, King M and Languino LR: Selective modulation of type 1 insulin-like growth factor receptor signaling and functions by betal integrins. J Cell Biol 166: 407-418, 2004.

3. Moro L, Arbini AA, Marra E and Greco M: Downregulation of BRCA2 expression by collagen type I promotes prostate cancer cell proliferation. J Biol Chem 280: 22482-22491, 2005.

4. Goel HL, Moro L, King M, Teider N, Centrella M, McCarthy TL, Holgado-Madruga M, Wong AJ, Marra E and Languino LR: Beta1 integrins modulate cell adhesion by regulating insulinlike growth factor-II levels in the microenvironment. Cancer Res 66: 331-342, 2006.

5. Moro L, Arbini AA, Marra E and Greco M: Upregulation of Skp2 after prostate cancer cell adhesion to basement membranes results in BRCA2 degradation and cell proliferation. J Biol Chem 281: 22100-22107, 2006.

6. Kohno $\mathrm{M}$ and Pouyssegur J: Targeting the ERK signaling pathway in cancer therapy. Ann Med 38: 200-211, 2006.

7. Shaw RJ and Cantley LC: Ras, PI(3)K and mTOR signalling controls tumour cell growth. Nature 441: 424-430, 2006.

8. Pouyssegur J, Volmat V and Lenormand P: Fidelity and spatiotemporal control in MAP kinase (ERKs) signalling. Biochem Pharmacol 64: 755-763, 2002.

9. Ochi H, Ogino H, Kageyama Y and Yasuda K: The stability of the lens-specific Maf protein is regulated by fibroblast growth factor (FGF)/ERK signaling in lens fiber differentiation. J Biol Chem 278: 537-544, 2003.

10. Bai XC, Lu D, Bai J, Zheng H, Ke ZY, Li XM and Luo SQ: Oxidative stress inhibits osteoblastic differentiation of bone cells by ERK and NF-kappaB. Biochem Biophys Res Commun 314: 197-207, 2004.

11. Bello-De Ocampo D, Kleinman HK, Deocampo ND and Webber MM: Laminin-1 and alpha6beta1 integrin regulate acinar morphogenesis of normal and malignant human prostate epithelial cells. Prostate 46: 142-153, 2001.

12. Cantley LC: The phosphoinositide 3-kinase pathway. Science 296: 1655-1657, 2002.

13. Vivanco I and Sawyers CL: The phosphatidylinositol 3-Kinase AKT pathway in human cancer. Nat Rev Cancer 2: 489-501, 2002.

14. Venkitaraman AR: Cancer susceptibility and the functions of BRCA1 and BRCA2. Cell 108: 171-182, 2002.

15. Liede A, Karlan BY and Narod SA: Cancer risks for male carriers of germline mutations in BRCA1 or BRCA2: a review of the literature. J Clin Oncol 22: 735-742, 2004.

16. Tavtigian SV, Simard J, Rommens J, et al: The complete BRCA2 gene and mutations in chromosome 13q-linked kindreds. Nat Genet 12: 333-337, 1996.
17. Wang SC, Shao R, Pao AY, Zhang S, Hung MC and Su LK: Inhibition of cancer cell growth by BRCA2. Cancer Res 62: 1311-1314, 2002.

18. Moro L, Perlino E, Marra E, Languino LR and Greco M: Regulation of beta1C and beta1A integrin expression in prostate carcinoma cells. J Biol Chem 279: 1692-1702, 2004.

19. Laemmli UK: Cleavage of structural proteins during the assembly of the head of bacteriophage T4. Nature 227: 680-685, 1970.

20. Juliano R: Cooperation between soluble factors and integrinmediated cell anchorage in the control of cell growth and differentiation. Bioessays 18: 911-917, 1996.

21. Wei J, Shaw LM and Mercurio AM: Regulation of mitogenactivated protein kinase activation by the cytoplasmic domain of the alpha6 integrin subunit. J Biol Chem 273: 5903-5907, 1998.

22. Shaw LM, Rabinovitz I, Wang HH, Toker A and Mercurio AM: Activation of phosphoinositide $3-\mathrm{OH}$ kinase by the alpha 6beta4 integrin promotes carcinoma invasion. Cell 91: 949-960, 1997.

23. Downward J: Mechanisms and consequences of activation of protein kinase B/Akt. Curr Opin Cell Biol 10: 262-267, 1998.

24. Engbring JA and Kleinman HK: The basement membrane matrix in malignancy. J Pathol 200: 465-470, 2003.

25. Stewart DA, Cooper CR and Sikes RA: Changes in extracellular matrix (ECM) and ECM-associated proteins in the metastatic progression of prostate cancer. Reprod Biol Endocrinol 2: 2, 2004.

26. Edlund M, Miyamoto T, Sikes RA, Ogle R, Laurie GW, Farach-Carson MC, Otey CA, Zhau HE and Chung LW: Integrin expression and usage by prostate cancer cell lines on laminin substrata. Cell Growth Differ 12: 99-107, 2001.

27. Cobb MH: MAP kinase pathways. Prog Biophys Mol Biol 71: 479-500, 1999.

28. Steelman LS, Pohnert SC, Shelton JG, Franklin RA, Bertrand FE and McCubrey JA: JAK/STAT, Raf/MEK/ERK, PI3K/Akt and $\mathrm{BCR}-\mathrm{ABL}$ in cell cycle progression and leukemogenesis. Leukemia 18: 189-218, 2004.

29. McCubrey JA, Steelman LS, Abrams SL, Lee JT, Chang F, Bertrand FE, Navolanic PM, Terrian DM, Franklin RA, D'Assoro AB, Salisbury JL, Mazzarino MC, Stivala F and Libra M: Roles of the RAF/MEK/ERK and PI3K/PTEN/AKT pathways in malignant transformation and drug resistance. Adv Enzyme Regul 46: 249-279, 2006.

30. Grill C, Gheyas F, Dayananth P, Jin W, Ding W, Qiu P, Wang L, Doll RJ and English JM: Analysis of the ERK1,2 transcriptome in mammary epithelial cells. Biochem J 381: 635-644, 2004.

31. Moro L, Fornaro M, Steger CA and Languino LR: Regulation of MCP-3 and BRCA2 mRNA expression levels by beta(1) integrins. Exp Mol Pathol 70: 239-247, 2001.

32. Hynes RO: Integrins: versatility, modulation, and signaling in cell adhesion. Cell 69: 11-25, 1992.

33. Hynes RO: Cell adhesion: old and new questions. Trends Cell Biol 9: M33-M37, 1999.

34. Marmorstein LY, Kinev AV, Chan GK, Bochar DA, Beniya H, Epstein JA, Yen TJ, Shiekhattar R: A human BRCA2 complex containing a structural DNA binding component influences cell cycle progression. Cell 104: 247-257, 2001.

35. Wang C, McCarty IM, Balazs L, Li Y and Steiner MS: Immunohistological detection of BRAF25 in human prostate tumor and cancer specimens. Biochem Biophys Res Commun 295: 136-141, 2002.

36. Wang C, McCarty IM, Balazs L, Li Y and Steiner MS: Cloning a cDNA encoding an alternatively spliced protein of BRCA2associated factor 35. Biochem Biophys Res Commun 295: 129-135, 2002.

37. Paweletz CP, Charboneau L, Bichsel VE, Simone NL, Chen T, Gillespie JW, Emmert-Buck MR, Roth MJ, Petricoin IE and Liotta LA: Reverse phase protein microarrays which capture disease progression show activation of pro-survival pathways at the cancer invasion front. Oncogene 20: 1981-1989, 2001.

38. Kreisberg JI, Malik SN, Prihoda TJ, Bedolla RG, Troyer DA, Kreisberg S and Ghosh PM: Phosphorylation of Akt (Ser473) is an excellent predictor of poor clinical outcome in prostate cancer. Cancer Res 64: 5232-5236, 2004.

39. Ghosh PM, Malik SN, Bedolla RG, Wang Y, Mikhailova M, Prihoda TJ, Troyer DA and Kreisberg JI: Signal transduction pathways in androgen-dependent and -independent prostate cancer cell proliferation. Endocr Relat Cancer 12: 119-134, 2005 . 
40. Yang G, Ayala G, De Marzo A, Tian W, Frolov A, Wheeler TM, Thompson TC and Harper JW: Elevated Skp2 protein expression in human prostate cancer: association with loss of the cyclindependent kinase inhibitor p27 and PTEN and with reduced recurrence-free survival. Clin Cancer Res 8: 3419-3426, 2002.

41. Grunwald V, De Graffenried L, Russel D, Friedrichs WE, Ray RB and Hidalgo M: Inhibitors of mTOR reverse doxorubicin resistance conferred by PTEN status in prostate cancer cells. Cancer Res 62: 6141-6145, 2002.

42. Maehama T and Dixon JE: The tumor suppressor, PTEN/ MMAC1, dephosphorylates the lipid second messenger, phosphatidylinositol 3,4,5-trisphosphate. J Biol Chem 273: 13375-13378, 1998.

43. Iacopino F, Lama G, Angelucci C and Sica G: Leuprorelin acetate affects ERK1/2 activity in prostate cancer cells. Int $\mathrm{J}$ Oncol 29: 237-247, 2006.

44. Xu C, Shen G, Yuan X, Kim JH, Gopalkrishnan A, Keum YS, Nair S and Kong AN: ERK and JNK signaling pathways are involved in the regulation of activator protein 1 and cell death elicited by three isothiocyanates in human prostate cancer PC-3 cells. Carcinogenesis 27: 437-445, 2006.
45. Xiao D, Choi S, Johnson DE, Vogel VG, Johnson CS, Trump DL, Lee YJ and Singh SV: Diallyl trisulfide-induced apoptosis in human prostate cancer cells involves c-Jun N-terminal kinase and extracellular-signal regulated kinase-mediated phosphorylation of Bcl-2. Oncogene 23: 5594-5606, 2004.

46. Kim KY, Choi KC, Park SH, Auersperg N and Leung PC: Extracellular signal-regulated protein kinase, but not c-Jun Nterminal kinase, is activated by type II gonadotropin-releasing hormone involved in the inhibition of ovarian cancer cell proliferation. J Clin Endocrinol Metab 90: 1670-1677, 2005.

47. Yu W, Liao QY, Hantash FM, Sanders BG and Kline K: Activation of extracellular signal-regulated kinase and c-Jun$\mathrm{NH}(2)$-terminal kinase but not $\mathrm{p} 38$ mitogen-activated protein kinases is required for RRR-alpha-tocopheryl succinate-induced apoptosis of human breast cancer cells. Cancer Res 61: 6569-6576, 2001. 